\title{
SYNDROME OF HYDROCEPHALUS IN YOUNG AND MIDDLE-AGED ADULTS. REVIEW OF THE LITERATURE AND ILLUSTRATIVE CASES
}

\author{
Kalevski Svetoslav, ${ }^{1,2}$ Peev Nikolay ${ }^{2}$ \\ ${ }^{1}$ Multiprofile Hospital "St. Anna”, Department Of Neurosurgery, Varna, Bulgaria \\ ${ }^{2}$ University Of Varna, School of medicine, Varna, Bulgaria
}

Primljen/Received 06. 01. 2015. god.

Abstract: Introduction: A multitude of underlying reasons result in hydrocephalus (HC), and its classification remains controversial. The current study looks at patients with the Syndrome of Hydrocephalus in Young and Middle-Aged adults (SHYMA) through a case series.

Patients and methods: We report 35 patients with HC referred to St. Anna Multiprofile Hospital during the period 2008-2012. Inclusion criteria were decompensated congenital hydrocephalus, (DCH), acquired hydrocephalus (AHC), or idiopathic hydrocephalus (IHC) in the age range of 16-55 years, treated with a ventriculo-peritoneal shunt (VPS) - 17 patients were treated with Strata Adjustable Delta Valve ("Strata" group) and 18 patients had Medtronic Orbis Sigma valves inserted ("Orbis Sigma” group).

Results: Eight patients $(22.86 \%)$ had DCH, 14 (40\%) had AHC, and 13 (37.14\%) had IHC.

Regardless the underlying cause for $\mathrm{HC}$, all the patients had similar symptoms, mainly related to gait in 26 (74.3\%), cognition in $30(85.7 \%)$, bladder control in 20 (57.14\%) and chronic headaches in 24 patients (68.57\%).

Symptomatic improvement was achieved in 34 of the shunted 35 patients $(97.14 \%)$, but the postoperative complications rate was found to be significantly lower in the "Strata" group.

Conclusion: The clinical presentation of hydrocephalus in the age $16-55$ years has common features presenting with syndrome of hydrocephalus in young and middle-aged adults as separate clinical entity.

VPS is a feasible treatment option in SHYMA. Due to the excessive, long standing ventriculomegaly, thus sensitive compliance of brain parenchyma and high tendency to develop subdural hematomas, adjustable VPS are advisable option.
Prihvaćen/Accepted 20. 03. 2015. god.

Key words: adult onset hydrocephalus, shunt, LOVA, SHYMA, subdural effusion.

\section{INTRODUCTION}

A multitude of underlying etiological reasons can result in hydrocephalus (HC), and the classification and terminology used in adult hydrocephalus remains controversial (1-4) åven a century after the first ever attempt at classification by Dandy $(5,6)$. Hydrocephalus is typically divided into age groups: Infants, Children and the Elderly being the main groups with well characterised presenting features in each group, such as excessive head enlargement and developmental delay in infants; headache, nausea, vomiting, altered mental status and drowsiness among children; and cognitive decline, gait apraxia and urinary incontinence in the elderly.

One group which has tended to be neglected is the age group which includes young to middle aged adults, and it has been proposed that patients in this age group who present with hydrocephalus represent a separate clinical category. The first systematic review in this age group was first described by S. Oi in mid-nineties as Longstanding Overt Ventriculomegaly in Adults (LOVA) (7). LOVA is a relatively new concept - a specific form of non-communicating hydrocephalus that often causes hydrocephalic dementia. Before this new clinical entity was proposed, patients with LOVA had been considered as normal pressure hydrocephalus (NPH) variants (8). Since then descriptions of LOVA presenting in young and middle-aged adults have been largely restricted to obstructive hydrocephalus secondary to aqueductal stenosis. However in the age group 16-55 years LOVA-like symptoms are not exclusive to patients with aqueductal stenosis. The presentation of hydrocephalus in young and middle-aged adults is of- 
ten atypical or subtle enough to be unrecognized as a clinical manifestation of hydrocephalus.

Cowan et al. in 2005 first described the syndrome of hydrocephalus in young and middle-aged adults (SHYMA) (9). They proposed the recognition of a single, clinically distinct syndrome of hydrocephalus in young and middle-aged adults, associated with ventriculomegaly with signs and symptoms that are age related and with a common feature set, unrelated to the primary aetiology of hydrocephalus.

The aim of the current study is to look at the common presenting features and treatment options in patients with hydrocephalus in this age group through a case series review, in order to shed light on the diagnosis and treatment of Longstanding Overt Ventriculomegaly in Adults (LOVA) and Syndrome of Hydrocephalus in Young and Middle-Aged adults (SHYMA).

\section{PATIENTS AND METHODS}

35 patients with HC were referred to "St. Anna" Multiprofile Hospital during the period 2008-2012. Inclusion criteria were decompensated congenital hydrocephalus, (DCH), acquired hydrocephalus (AHC), or idiopathic hydrocephalus (IHC) within the age range of 16-55 years. Exclusion criteria in the ACH group were: patients who developed acute HC secondary to diseases such as subarachnoid haemorrhage, tumours, meningitis and intraventricular haemorrhage. The diagnosis of symptomatic hydrocephalus was made on the basis of history, signs and symptoms, computed tomography (CT) or magnetic resonance imaging (MRI) documented hydrocephalus with evidence of elevated intracranial pressure (ICP).

Patients were classified as having $\mathrm{DCH}, \mathrm{AHC}$, or IHC on the basis of history and clinical examination. Patients were included in the DCH group if their head circumference was at the $97^{\text {th }}$ percentile or more for sex and height. Usually a thoroughly taken history for the patients with DHC revealed problems in early childhood consistent with the present symptoms. Those in the AH group had medical histories including head trauma, meningitis, encephalitis, or brain tumour. Head trauma was considered significant if it resulted in loss of consciousness and hospitalization. Patients not meeting the criteria for the two previous groups were considered to have IH.

The age of symptom onset was determined by asking patients and family, when they first noticed symptoms, or if possible, through previous medical records. The age of diagnosis was defined as the point at which the patient's ventriculomegaly, seen on CT or MRI scan, was associated with their symptoms. The time-to-diagnosis (TTD) was determined by calculating the difference between the age of diagnosis and the age of symptom onset. All patients underwent surgery with placement of either a flow regulated Medtronic Orbis Sigma valve or with adjustable pressure Strata valve (Medtronic, US). Patients who underwent shunt surgery were followed up by a neurosurgeon weekly in the first month, then on the 2, 3 and 6 months, and yearly thereafter.

The outcomes were assessed by determining the extent of symptom resolution. Complete improvement was deWned as complete resolution of all presenting symptoms. Partial improvement was deWned as complete resolution of at least one of the presenting symptoms. Patients were classiWed as having no improvement if all of their pre-treatment symptoms persisted at follow-up.

The patient were divided in 2 groups: Group 1 patients shunted with flow regulated valve Medtronic Orbis Sigma; Group 2 - patients shunted with Strata Adjustable Delta Valve. The Strata valve had been initially set to maximal pressure -2.5 and reduced with 0.5 afterwards on the weekly follow ups until the resolution of the symptoms continues. Complications rate in the two groups in terms of subdural hematoma formation was evaluated and compared.

Statistical analysis to compare the rate of complication in the two groups of patients was performed via two-sided $t$ test or one-way analysis of variance (ANOVA). Data was presented as the mean \pm SEM. Differences were considered significant when $\mathrm{P}<0.05$.

\section{RESULTS}

We evaluated 35 patients (18 men; 17 women) between 2008 and 2012. Eight patients (22.86\%) had DCH, 14(40\%) had AHC, and 13 (37.14\%) had IHC. The causes of AHC included head trauma $(n=7)$, subarachnoid haemorrhage $(n=5)$, meningitis $(n=2)$. The reason for the $\mathrm{HC}$ in the DHC was aqueductal stenosis. All the patients with no apparent reason for the HC were classified as IHC.

The mean age at of the patients was 47.2 years (range 16-65). The mean TTD for all patients was 7.7 years (range 0.7-29.6 years).

Symptoms at the time of diagnosis were related to gait in $26(74.3 \%)$, cognition in $30(85.7 \%)$, bladder control in $20(57.14 \%)$ and chronic headaches in 24 patients $(68.57 \%)$. The other symptoms were visual changes in three $(8.57 \%)$, nausea/vomiting in three $(8.57 \%)$, alteration in consciousness in $2(5.71 \%)$ and seizure in 1 patient $(2.86 \%)$.

Disturbances in gait were most frequently described as clumsiness, difficulty on uneven surfaces, and difficulty with stairs. Physical Wndings of subtle gait abnormalities (widened base or stance, shortened stride length, impaired tandem stance or walk) were seen in $26(74.3 \%)$ of the patients, but overt gait apraxia was absent in the examined group. 
Cognitive disturbance, varying from mild cognitive impairment, resulting mainly in poor organizational skills, or dependence on lists, to frank dementia was found in 30 of the patients $(85.71 \%)$. The main urinary symptoms found in $20(57.14 \%)$ patients were frequency and urgency and 4 only (11.43\%) patients had true urinary incontinence.

All the patients were treated with ventriculo-peritoneal shunt placement (VPS) - 17 patients were treated with Strata Adjustable Valve ("Strata" group) and the rest 18 patients had Medtronic Orbis Sigma ("Orbis Sigma" group).

Symptomatic improvement was achieved in 34 out of 35 patients shunted (97.14\%). Follow up of the $100 \%$ of the patients was achieved up to the $6^{\text {th }}$ month. All of the 34 patients preserved the symptomatic improvement at $6^{\text {th }}$ months follow-up. The VPS (Medtronic Orbis Sigma) in one of the patients was removed due to significant over drainage and formation of significant bilateral effusions, and the patient was discharged with no improvement, but no deterioration. In the "Strata" group only one patient $(5.88 \%)$ developed subdural hematoma postoperatively due to the wrong protocol being followed - the valve had been set directly to 0.5 , but not to 2.5 with slow decrease afterwards. Shunt revision was required in 3 of the patients (17.64\%).

In the "Orbis Sigma" group, subdural haematomas were found in $6(33.33 \%)$ patients and $10(55.55 \%)$ patients needed shunt revision. All the hematomas were treated within the same admission. The revisions of the VPS were performed within the initial admission (10/13) or within the first month after the discharge (3/13).

The following table (Table 1) presents the number of the patients from the different groups that had revision surgery and $\mathrm{SDH}$.

\section{Illustrative cases}

\section{Case 1 (DHC, obstructive, aqueductal stenosis)}

A 42-year old man presented with progressive headache, gait difficulty, memory loss, and urinary frequency. The head circumference was found to be above

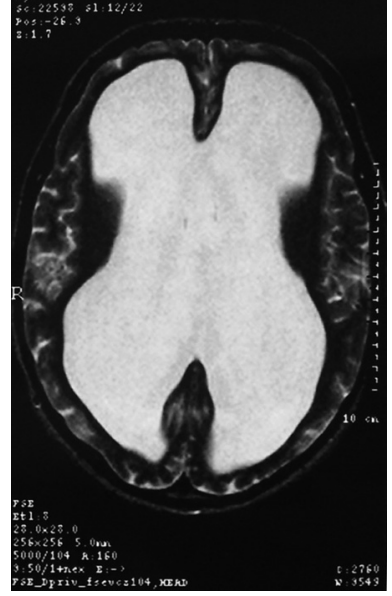

Figure 1. Isolated ventriculomegaly of the lateral ventricles

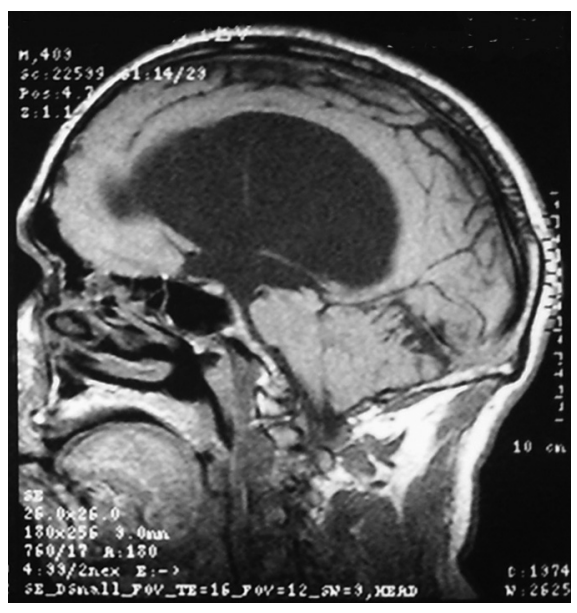

Figure 2. Aqueductal stenosis

the $97^{\text {th }}$ percentile. A thorough history taking revealed that the patient had had meningitis in early childhood after which he became deaf and mute. MRI scan revealed isolated ventriculomegaly of the lateral and third ventricles with normal fourth ventricle (Figure 1). confirming aqueductal stenosis (Figure 2). The patient was operated and the hydrocephalus was shunted with Medtronic Orbis Sigma valve. The postoperative scan performed 7 days after the shunt surgery revealed massive bilateral subdural collections (Figure 3). After clinical discussion the VPS it was decided that the shunt be removed and the subdural collections to be monito-

Table 1. The number of the patients from different groups that had revision surgery

\begin{tabular}{|l|c|c|c|}
\hline & DHC $(\mathrm{n}=8)$ & AHC $(\mathrm{n}=14)$ & IHC $(\mathrm{n}=13)$ \\
\hline Orbis Sigma $(\mathrm{n}=18)$ & 4 & 7 & 7 \\
\hline Strata $(\mathrm{n}=17)$ & 4 & 7 & 6 \\
\hline SDH (Orbis Sigma) $(\mathrm{n}=6)$ & 1 & 3 & 2 \\
\hline SDH (Strata) $(\mathrm{n}=1)$ & 1 & 0 & 0 \\
\hline REVISION (Orbis Sigma) $(\mathrm{n}=10)$ & 2 & 4 & 4 \\
\hline REVISION (Strata) $(\mathrm{n}=3)$ & 1 & 1 & 1 \\
\hline
\end{tabular}




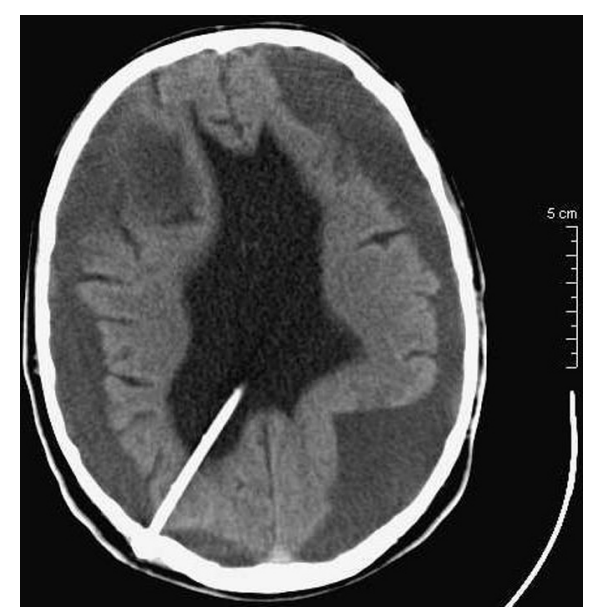

Figure 3. Massive bilateral subdural collections

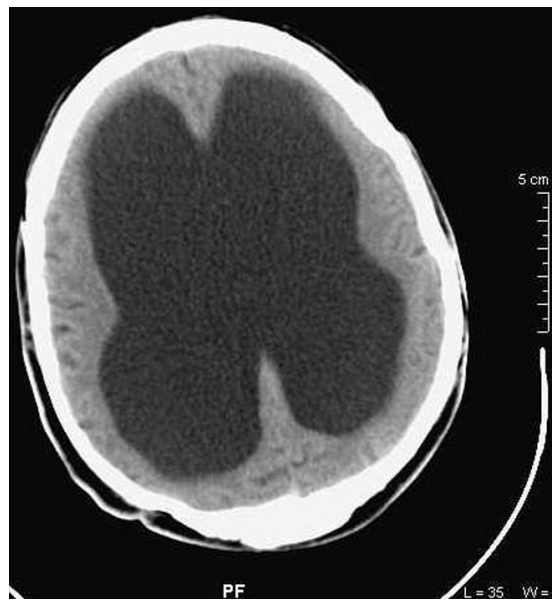

Figure 4. Three months after the shunt removal, the subdural collections had resolved

red with serial CT scans. Three months after the shunt removal, the subdural collections had resolved (Figure 4) and the patient reported no headaches, with improved gait and urinary control. Patient remained clinically stable with no complains on the sixth month follow up visit.

\section{Case 2 (IHC)}

A 28-year old man presented with one year history of headache, dizziness, difficulties finding words, lower limbs weakness and urinary incontinence. The conversation with his relatives revealed learning difficulties and mental retardation during the childhood. MRI investigation revealed excessive dilatation of the all four ventricles (Figure 5A and 5B). Intracranial pressure measured in recumbent position pre-operatively revealed an ICP of $6 \mathrm{~mm} \mathrm{Hg}$. After clinical discussion it was decided the hydrocephalus to be treated with Strata Adjustable Valve. The valve was intra-operatively set at 1.0. CT scan on the sixth post-operative day showed an acute epidural hematoma (Figure 6)

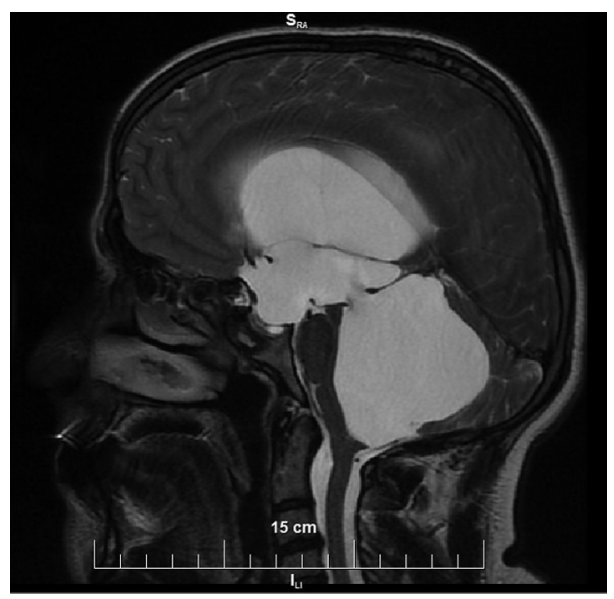

Figure 5A. Excessive dilatation of the all four ventricles

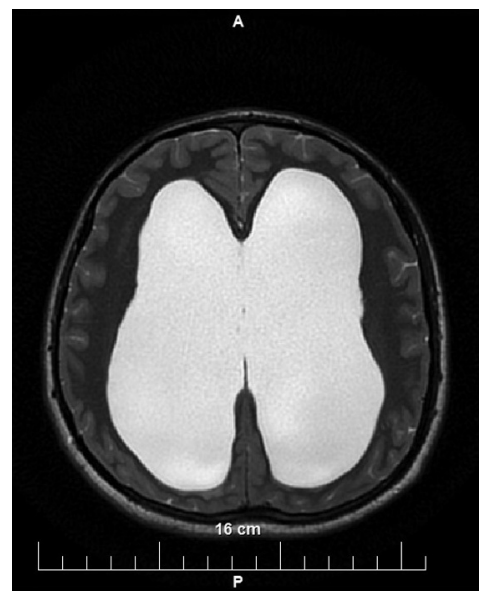

Figure 5B. Excessive dilatation of the lateral ventricles

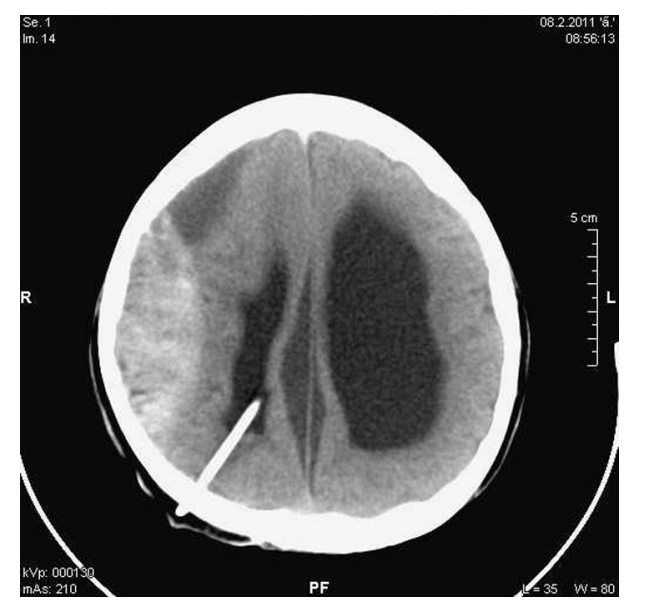

Figure 6. Acute epidural hematoma

that had to be evacuated urgently. The valve was set intra-operatively to 2.0 . The postoperative period went uneventfully. Patient was discharged with significant improvement - no headaches and dizziness, improved word finding, improved gait and urinary control, which remained unchanged on the sixth month follow up visit. 


\section{Case 3 (ACH)}

38 year-old female presented in Emergency Department after generalized tonic-clonic seizure. CT scan demonstrated a moderate-sized acute on chronic subdural hematoma, excessively enlarged lateral and third ventricle and VP shunt system (Figure 7A and 7B). The conversation with the relatives, together with the medical documentation revealed that the patient had an implanted Strata Adjustable Valve back in 2009 , set at 1.5 . The reason for shunt surgery had been complaints of headaches, memory problems and urinary urgency. Detailed questioning of the relatives also revealed multiple head injuries during early childhood with loss of consciousness. A burr hole evacuation of the subdural hematoma was initially attempted. However due to a $4 \mathrm{~mm}$ thick parietal haematoma capsule found intra-operatively, the burr hole was converted to a mini-craniotomy (Figure 8). The Valve was set to 2.0 postoperatively, which resulted in transient postoperative urinary urgency and night bed wetting, which subsided gradually over a 2 week period. The patient was

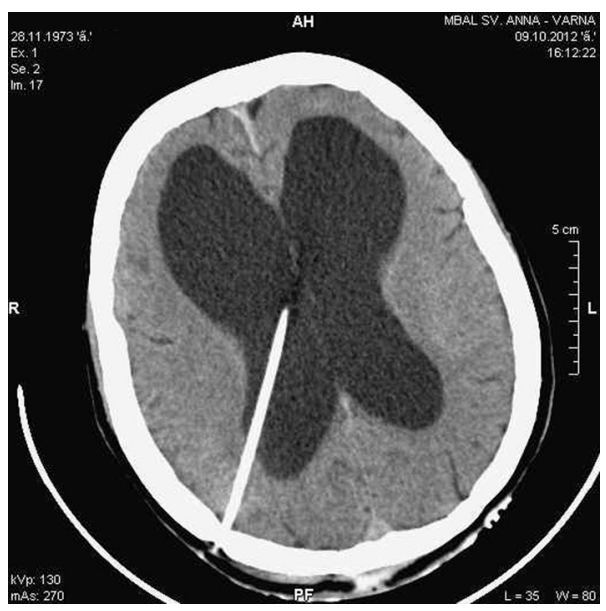

Figure 7A. Excessively enlarged lateral ventricles and VP shunt system

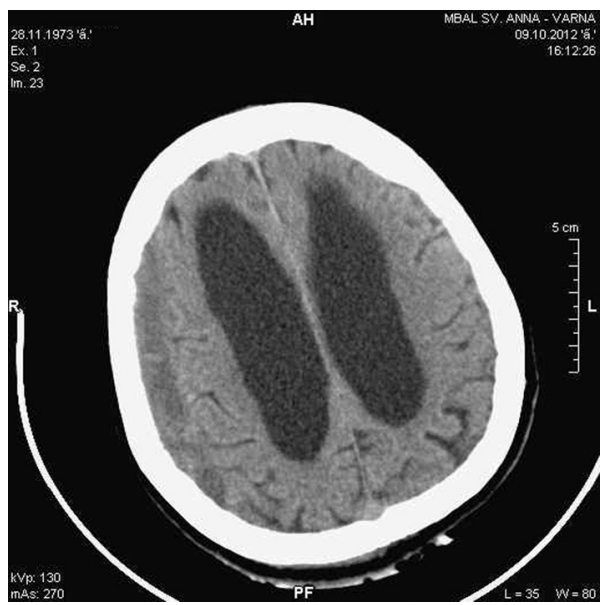

Figure 7B. Moderate-sized acute on chronic subdural hematoma, excessively enlarged lateral ventricles

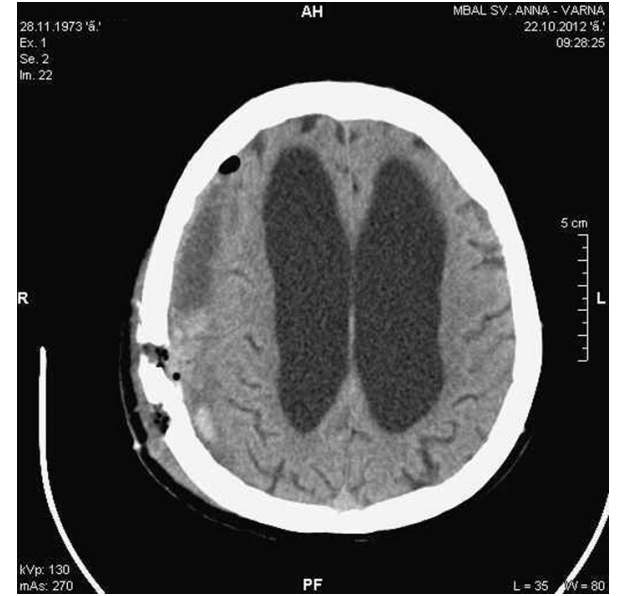

Figure 8. Mini-craniotomy for evacuation of the hematoma

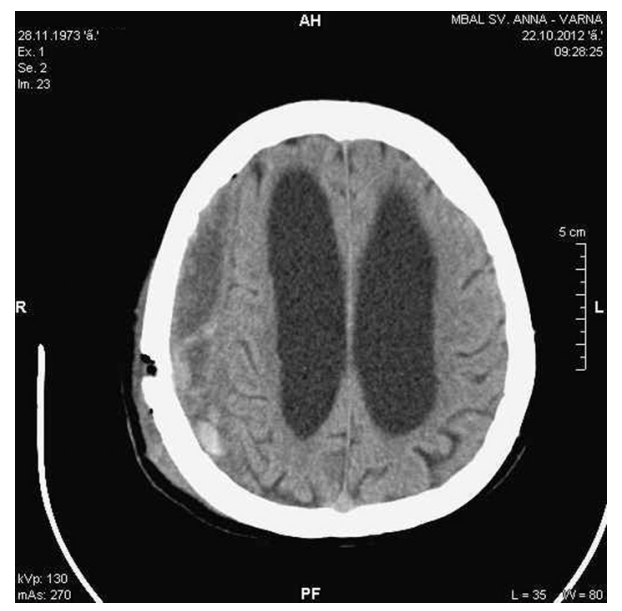

Figure 9. Postoperative follow up CT scan

discharged on anticonvulsant treatment. The postoperative follow up CT scans (Figure 9) on the $1^{\text {st }}$ and $2^{\text {nd }}$ and $6^{\text {th }}$ month revealed that the size of the subdural hematoma was unchanged, but the patient remained free of symptoms.

\section{DISCUSSION}

A multitude of underlying etiological reasons can cause hydrocephalus (HC). Its classification and terminology is still controversial and a widely accepted consensus is still due to be achieved.

The pathophysiology of hydrocephalus (HC) first started in the beginning of the previous century with the work of Dandy and Blackfan (5). In 1913 they had first introduced the term "Internal Hydrocephalus" and also described the main features of the so called Communicating and Non-communicating Hydrocephalus. By 1919 Dandy (6) had developed an experimental animal model in order to study and develop treatment for HC. Since that first classification, there are numerous attempts at $\mathrm{HC}$ classifications, reflecting different aspects of the problem, but 100 years after the Dandy's 
and Blackfan's work, despite the many major achievements led to many classifications covering different aspects of HC, the ideal comprehensive classification covering all the aspects remains elusive. Hence the term hydrocephalus generally represents a complex pathophysiological entity with one main characteristic disturbed cerebrospinal fluid (CSF) turnover, with complex, not well understood and on many occasions intuitive treatment.

Despite the first Dandy and Blackfan classification is already a century old, it remains popular and still in use. The authors defined two main subgroups of $\mathrm{HC}$ - communicating and non-communicating, simplistically based on the ability of a dye injected to the lateral ventricles to be isolated in the lumbar subarachnoid space by a lumbar puncture, respectively to evaluate the communication of the lateral ventricles with the lumbar subarachnoid space. Later on Russell (10) further developed the idea with the introduction of the terms obstructive and non-obstructive hydrocephalus. The obstruction is defined as a condition of disturbed CSF circulation due to a blockage at any point in the major CSF pathway including the ventricular system and cistern/subarachnoid apace, hence the causes for non-obstructive hydrocephalus are limited to either CSF overproduction by choroid plexus papilloma or CSF malabsorption due to sinus thrombosis. So after a thorough reading of these two authors it would appear that the terms communicating/non-communicating and obstructive/non-obstructive hydrocephalus are not identical. While communicating/non communicating state is based simply on the ability of a dye to move freely from the lateral ventricles to the lumbar subarachnoid space, the obstruction defined by Russell is at any region in the major CSF pathway including the ventricular system, and entire cistern/subarachnoid space. Hence the term non-obstructive hydrocephalus should be assigned only for pathology causing CSF overproduction like choroid plexus papilloma or CSF malabsorption due to sinus thrombosis.

In 1960 Ransohoff (11) revised the Dandy's communicating/non communicating $\mathrm{HC}$ classification based on his experiments. The author believed that all of the HC forms involve obstruction of the CSF pathway somewhere between its point of production in the choroids plexus and its point of absorption in the arachnoid villi. Hence he termed the Dandy's noncommunicating $\mathrm{HC}$ as "intraventricular obstructive $\mathrm{HC}^{\prime}$ while the communicating $\mathrm{HC}$ had been renamed to "extraventricular obstructive HC".

Later Raimondi (2) defined hydrocephalus as a pathologic increase in intracranial CSF volume - intra- or extraparenchymal, independent of hydrostatic or barometric pressure. He literally interpreted $\mathrm{HC}$ as "water head" and considered all the pathological conditions leading to accumulation of water in the intracranial compartments. Thus he classified hydrocephalus into intraparenchymal (cerebral oedema) and extraparenchymal, with the extraparenchymal types sub- classified into subarachnoid, cisternal, and intraventricular forms.

All these and many other classifications focus on the site of obstruction or the compartment of CSF accumulation, which was a reason why Satoshi Takahashi, in a comment in Journal of Hydrocephalus (12), attempted to unite all these and many other classifications into a classification in which any type of hydrocephalus could fit. In his comment he differentiated another two major groups of HC classifications, namely classifications that focus on specific developmental stages (ex. neonates, infants, or adults) and also classifications that described some specific forms of hydrocephalus like NPH, LOVA, etc.

The developmental and chronological trends in classifying hydrocephalus are reflected in the work of Shizuo Oi.

The developmental trend is reflected in the so called "Evolution theory in cerebrospinal fluid dynamics" proposed by Oi in 2006 (13). The author proposed the term "minor pathway" — the pattern of ventriculo-cisternography in neonatal/infantile cases revealed a predominantly intra-parenchymal pattern of CSF circulation, unlike the adult type of CSF circulation which is termed "Major pathway". This was the primary reason proposed by the author for the high incidence of "failure to arrest hydrocephalus" by neuroendoscopic ventriculostomy in fetal, neonatal and infantile periods while the major CSF pathway is not developed, the minor pathway plays a significant role in the neonates. Based on these findings the author postulated "minor pathway hydrocephalus". The development of the "major pathway" Oi juxtaposed with the evolutional findings in the development of the CSF pathways, as in the animals, ex. rats where the minor CSF pathway predominates, towards the matured adult human brains where the major CSF pathway is predominant. This gives the ground the theory to be termed "Evolution theory in cerebrospinal fluid dynamics”.

The chronological trend classifying HC is reflected by the Perspective Classification of Congenital Hydrocephalus (PCCH) (14). This classification is an attempt to determine the factors for the postnatal prognosis of fetal hydrocephalus - in this paper the author believed that the prognosis in fetal hydrocephalus should be determined not only with morphological analysis of prenatal diagnostic imaging, but also in combination with the degree of brain parenchymal damage and $\mathrm{HC}$ progression. Based on that Oi described five clini- 
co-embryological stages [PCCH Stage I-V] with different prognoses in $\mathrm{HC}$.

As classification dealing with specific forms of $\mathrm{HC}$ could be: Normal pressure hydrocephalus (NPH), Longstanding overt ventriculomegaly in adult (LOVA), Hydrocephalus-parkinsonism complex, etc. (15), The syndrome of hydrocephalus in young and middle-aged adults (SHYMA), etc.

CSF circulation and turnover is a complex process and is described by many variables and is dependent on a multitude of factors which complicates attempts at a unifying classification system. Based on the systematic review of almost 10000 publications from the period of 1950-2008 in the HC area, and also based on his own experimental and clinical work, in 2010 Oi proposed "Multi-categorical Hydrocephalus classification, attempting to cover all the aspects of the $\mathrm{HC}^{\text {" }}$ (16). Each $\mathrm{HC}$ case according to this classification is confronted to ten categories with multiple subcategories, with a final count of $54 \mathrm{HC}$ subtypes listed. If one would wish to cover all the possible combinations in this classification, there would be theoretically $72,576,000$ patterns of hydrocephalus classified.

As classification dealing with specific forms of HC could be pointed Normal pressure hydrocephalus (NPH) (17), Longstanding overt ventriculomegaly in adult (LOVA), Hydrocephalus-parkinsonism complex (15), The syndrome of hydrocephalus in young and middle-aged adults (SHYMA), etc.

Longstanding overt ventriculomegaly in adult (LOVA) is a specific form of non-communicating hydrocephalus that often causes hydrocephalic dementia. It is a unique category of hydrocephalus first presented by Oi in the mid-1990's. Before this new category was proposed, patients with LOVA might have been considered within the spectrum of normal pressure hydrocephalus (NPH) (17-20).

But descriptions of LOVA presentation in young and middle-aged adults have largely been restricted to obstructive hydrocephalus due to aqueductal stenosis. Because adults in this age range have been included in cohorts of predominately elderly patients with NPH $(18,21,22)$ the clinical presentation of young adults has not been differentiated until Cowan et al. (9) described in 2005 a new subgroup of HC patients - hydrocephalus in young and middle-aged adults. They proposed the recognition of a single, clinically distinct syndrome of hydrocephalus in young and middle-aged adults (SHYMA), which is associated with ventriculomegaly and signs and symptoms that are age related and mostly similar, regardless of the aetiology of the hydrocephalus. So according to the authors, LOVA patient group - those with obstructive hydrocephalus due to aqueductal stenosis, appear to be a subset of
SHYMA patient group, which comprise chronic HC patients not only with decompensated $\mathrm{HC}$ due to aqueductal stenosis, but $\mathrm{HC}$ due to obstruction elsewhere but aqueduct, also non obstructive $\mathrm{HC}$ forms and also idiopathic HC.

The results from the followed in our investigation group of 35 patients is concordant with the findings of Cowan et al. The majority of the patients present with the following 4 symptoms regardless of the etiology. Namely mild gait disturbance $(74.3 \%)$, but not overt gait apraxia; different extent of cognitive decline (85.7\%); bladder control problems (57.14\%), but only rarely overt incontinence; chronic headache (68.57\%). The other symptoms that were additionally supporting the diagnosis were visual changes $(8.57 \%)$, nausea/vomiting $(8.57 \%)$, alteration in consciousness $(5.71 \%)$ and seizure in 1 patient $(2.86 \%)$. The common symptoms in the three subgroups, regardless of the causing the $\mathrm{HC}$ pathology, suggests that the age is significant determinant of the development and the clinical presentation of the disease.

The good results on the follow ups showed that the VPS is a feasible option for this subgroup of $\mathrm{HC}$ patients, but the rate of the post-shunting hematoma formation suggests that adjustable shunts should be used in order to reduce the rate of complications, especially with the patients with excessive ventriculomegaly due to chronic $\mathrm{HC}$, due to the sensitive compliance of their brain parenchyma (23) - these patients have high tendency to develop bilateral subdural hematoma when treated with improperly chosen shunt systems.

There are investigations clearly stating the role of the resistance to outflow and brain compliance as important parameters in the hydrocephalus patho-physiology, thus important parameters for appropriate shunt selection. Some milestone studies based on modern flow-sensitive MRI protocols establish the brain compliance as very important parameter for the chronic hydrocephalus patients $(24,25,26)$.

\section{CONCLUSION}

Based on the available literature and also our investigation, we accept the age as a major determinant of the clinical expression of the $\mathrm{CH}$. The clinical presentation of hydrocephalus in young and middle-aged adults has common features that allow differentiating a subgroup of $\mathrm{HC}$ patients presenting with syndrome of hydrocephalus in young and middle-aged adults (SHYMA) as separate clinical entity.

VPS is a feasible treatment option in SHYMA. Due to the excessive and long standing ventriculomegaly that these patients have, which suggests sensitive compliance of brain parenchyma, respectively high 
tendency to develop subdural hematomas when treated with improperly chosen shunt systems, adjustable VPS are advisable to be used for their treatment.
Abbreviations
AHC - acquired hydrocephalus
ANOVA - analysis of variance
CSF - cerebrospinal fluid
CT - computed tomography
DCH - decompensated congenital hydrocephalus
HC - hydrocephalus

IHC - idiopathic hydrocephalus

ICP - elevated intracranial pressure

LOVA - Longstanding Overt Ventriculomegaly in Adults

MRI - magnetic resonance imaging

NPH - normal pressure hydrocephalus

PCCH - Perspective Classification of Congenital Hydrocephalus

SHYMA - Syndrome of Hydrocephalus in Young and Middle-Aged adults

TTD - time-to-diagnosis

VPS - ventriculo-peritoneal shunt

\title{
Sažetak
}

\section{SINDROM HIDROCEFALUSA KOD MLADIH I OSOBA SREDNJE ŽIVOTNE DOBI — PREGLED LITERATURE I PRIKAZI SLUČAJEVA}

\author{
Kalevski Svetoslav, ${ }^{1,2}$ Peev Nikolay ${ }^{2}$ \\ ${ }^{1}$ Multiprofile Hospital "St. Anna”, Department Of Neurosurgery, Varna, Bulgaria \\ ${ }^{2}$ University Of Varna, School of medicine, Varna, Bulgaria
}

Uvod: Veliki broj stanja za posledicu ima hidrocefalus (HC), a njegova klasifikacija i dalje ostaje kontroverzna. Ova studija obuhvata mlade i sredovečne pacijente sa sindromom hidrocefalusa (SHYMA), i prikaze reprezentativnih slučajeva.

Pacijenti i metode: Prikazujemo 35 pacijenata sa HC, lečenih u bolnici „St. Anna“, u periodu od 2008. do 2012. godine. Kriterijumi za uključivanje u studiju su dekompenzovani urođeni hidrocefalus (DCH), stečeni hidrocefalus (AHO), ili idiopatski hidrocefalus (IHH), u starosnoj dobi od 16-55 godina, tretirani ventriculo-peritonealnim šantom (VPS) - 17 bolesnika je lečeno Strata podesivim Delta valvulama („Strata“ grupa) i 18 pacijenata Medtronic Orbis Sigma valvulama („Orbis Sigma“ grupa).

Rezultati: Osam pacijenata $(22.86 \%)$ je imalo DCH, 14 (40\%) je imalo AHO i 13 (37.14\% ) IHC. Bez obzira na osnovni uzrok hidrocefalusa, svi pacijenti su

\section{REFERENCES}

1. Mori K. Current concept of hydrocephalus: evolution of new classifications. Childs Nerv Syst.1995; 11(9): 5231.

2. Raimondi AJ. A unifying theory for the definition and classification of hydrocephalus. Childs Nerv Syst. 1994; 10(1): 2-12.

3. Rekate HL. A consensus on the classification of hydrocephalus: its utility in the assessment of abnormalities of cerebrospinal fluid dynamics. Childs Nerv Syst. 2011; 27(10): 1535-41.

4. Rekate H. Hydrocephalus: classification and athophysiology. In: McLone D, editor. Pediatric neurosurgery: surgery of imali slične simptome, koji su se uglavnom odnosili na hod kod 26 (74,3\%), kognitivne funkcije kod 30 $(85,7 \%)$, kontrolu mokrenja kod $20(57,14 \%)$ i hronične glavobolje kod 24 pacijenta $(68,57 \%)$. Simptomatsko poboljšanje ostvareno je kod 34 od 35 šantovanih pacijenata $(97,14 \%)$, ali je utvrđeno da je stopa postoperativnih komplikacije značajno niža u „Strata“ grupi.

Zaključak: Klinička prezentacija hidrocefalusa u dobi od 16-55 godina, ima zajednička obeležja prezentovana sindromom hidrocefalusa kod mladih i sredovečnih odraslih kao zasebnim kliničkim entitetima. VPS je moguća opcija lečenja kod SHYMA. Zbog prekomerne dugogodišnje ventrikulomegalije, osetljivosti moždanog parenhima i visoke sklonosti za razvoj subduralnog hematoma, podesivi VPS su poželjna opcija.

Ključne reči: hidrocefalus odraslih, šant, LOVA, SHYMA, subduralni izliv.

the developing nervous system, $4^{\text {th }}$ ed. Philadelphia: Saunders; 2000. pp 2535.

5. Dandy WE, Blackfan KD. Internal hydrocephalus. An experimental, clinical and pathological study. Am J Dis Child. 1914; 8: 406-82.

6. Dandy WE. Experimental hydrocephalus. Ann Surg. 1919; 70: 129-42.

7. Oi S, Shimoda M, Shibata M, et al. Pathophysiology of long-standing overt ventriculomegaly in adults. J Neurosurg. 2000; 92(6): 933-40.

8. Oi S. Hydrocephalus chronology in adults: confused state of the terminology. How should "normal-pressure hydrocephalus" be defined? Crit Rev Neurosurg. 1998; 8(6): 346-56. 
9. Cowan JA, McGirt MJ, Woodworth G, Rigamonti D, Williams MA. The syndrome of hydrocephalus in young and middle-aged adults (SHYMA). Neurol Res. 2005; 27(5): 540-7.

10. Russell DS. Observation on the Pathology of Hydrocephalus. In: Medical research council. Special report, series No. 265. London: His Majesty's Stationery Office; 1949. pp112-3.

11. Ransohov J, Shulman K. Fishman RA. Hydrocephalus: A review of etiology and treatment. J Pediatr. 1960; 56: 499-511.

12. Takahashi S. Consideration of Modern Hydrocephalus Classification Childs Nerv Syst. 2011; 27: 1523-33.

13. Oi S, Di Rocco C. Proposal of "evolution theory in cerebrospinal fluid dynamics" and minor pathway hydrocephalus in developing immature brain. Childs Nerv Syst. 2006; 22 (7): 662-9.

14. Oi S, Honda Y, Hidaka M, Sato O, Matsumoto S. Intrauterine high-resolution magnetic resonance imaging in fetal hydrocephalus and prenatal estimation of postnatal outcomes with “perspective classification". J Neurosurg. 1998; 88(4): 685-94.

15. Oi S, Kim DK, Hidaka M. "Hydrocephalus-parkinsonism complex": progressive hydrocephalus as a factor affecting extrapyramidal tract disorder - an experimental study. Child's Nerv Syst. 2004; 20: 37-40.

16. Oi S. Classification of hydrocephalus: critical analysis of classification categories and advantages of "Multi-categorical Hydrocephalus Classification” (Mc HC). Childs Nerv Syst. 2011; 27: 1523-33.

17. Hakim S, Adams RD. The special clinical problem of symptomatic hydrocephalus with normal cerebrospinal fluid pressure. Observations on cerebrospinal fluid hydrodynamics. J Neurol Sci. 1965; 2(4): 3077.

\section{Correspondence to /Autor za korespondenciju}

Prof. Dr. Svetoslav Kalevski, MD, PhD, DSc

Dep. Neurosurgery

Medical University of Varna

55 "Marin Drinov" Str.

BG-9002 Varna,

Bulgaria

Mobile:+359 888212387

E-mail: dr_kalevski@abv.bg

Fax:+359 52355553

Nikolay Angelov Peev, MD, PhD (Neurosurgery),

FRCS (England)

Consultant Neurosurgeon

Belfast HSC Trust

Mobile: +44 (0) 7709674083

E-mail: nikolay.a.peev@gmail.com
18. Barnett GH, Hahn JF, Palmer J. Normal pressure hydrocephalus in children and young adults. Neurosurgery. 1987; 20(6): 904 .

19. Bret P, Chazal J. Chronic normal pressure hydrocephalus in childhood and adolescence. A review of 16 cases and reappraisal of the syndrome. Childs Nerv Syst. 1995; 11(12): 6871.

20. Kiefer M, Eymann R, Steudel WI. LOVA hydrocephalus - A new entity of chronic hydrocephalus. Nervenarzt. 2002; 73(10): 972-81.

21. Larsson A, Wikkelso C, Bilting M, Stephensen H. Clinical parameters in 74 consecutive patients shunt operated for normal pressure hydrocephalus. Acta Neurol Scand. 1991; 84(6): 475-82.

22. Vanneste J, Augustijn P, Tan WF, Dirven C. Shunting normal pressure hydrocephalus: the predictive value of combined clinical and CT data. J Neurol Neurosurg Psychiat. 1993; 56(3): 251-6.

23. Levine DN. Intracranial pressure and ventricular expansion in hydrocephalus: Have we been asking the wrong question? J Neurol Sci. 2008; 269(1-2): 1-11.

24. Kiefer M, Eymann R. Clinical proof of the importance of compliance for hydrocephalus pathophysiology. Acta Neurochir Suppl. 2010; 106: 69-73.

25. Greitz D. Radiological assessment of hydrocephalus: New theories and implications for therapy Neurosurg. Rev. 2004; 27 (3): 145-65.

26. Bateman GA, Lev CR, Schofield P, Wang Y, Lovett EC. The venous manifestations of pulse wave encephalopathy: Windkessel dysfunction in normal aging and senile dementia. Neuroradiology. 2008; 50(6): 491-7. 